\title{
Analysis and ways of reducing electricity losses in the electric power systems of industrial enterprises
}

\author{
Olimjon Toirov ${ }^{1}$, Kamoliddin Alimkhodjaev ${ }^{2}$, and Akhror Pardaboev ${ }^{3}$ \\ ${ }^{1}$ Tashkent State Technical University, DSc., Prof. Head of the Department of Electrical machine, Tashkent, 100095, Uzbekistan \\ ${ }^{2}$ Tashkent State Technical University, DSc., Professor of the Department of Electrical machine, Tashkent, 100095, Uzbekistan \\ ${ }^{3}$ Tashkent State Technical University, Researcher, Department of Electrical machine, Tashkent, 100095, Uzbekistan
}

\begin{abstract}
As a result of the analysis, ways to reduce electricity losses in the system of its production, distribution, transmission and consumption in industrial enterprises have been identified. The problem of recompense of jet capacity always occupied the important Place in the general complex problems of increasing transfer efficiency, distribution and consumption of electric energy. The correct decision such problems appreciably predetermines economy monetary and material resources, electrical supply improvement of quality. The main recompense problems of jet capacity should be considered with the account of modern views and taking into account new technical decisions in this area. The analysis of electricity losses in the Republic and increasing their energy efficiency while optimizing the consumption of reactive power is made. Recommendations have been developed to reduce losses on the line and in-plant losses of electricity.
\end{abstract}

\section{Introduction}

Since the first days of independence of the Republic of Uzbekistan, the process of efficient use of energy resources has been ranked as a matter of national importance. In this regard, in the electric power industry, along with the growth of electricity production through the construction of new (including stations with alternative energy sources) and the modernization of old power plants, special attention is paid to the rational use of electricity in its production, transmission, distribution and use by consumers. In this regard, a special place is occupied by the development of measures to reduce energy losses at certain stages of the technological process from production to consumption of electric energy.

Research on reducing energy losses in the national economy, from the stage of electricity production to its conversion into useful work by the consumer, is usually considered separately [1-5]: energy losses during its production at stations (losses during fuel combustion, in a turbine, generator, on tires, transformer); losses on a line (power transmission lines, substations); in-plant losses.

Reducing energy losses in the production of electricity at thermal power plants (TPP) is achieved by upgrading them using equipment built on the basis of the latest achievements of science and technology (Navoi, Talimarjan TPP and Tashkent TPP). The efficiency of using any type of fuel for conversion to electrical energy is estimated by the specific consumption of conventional fuel for the production of a unit of electrical
energy.Despite the fact that the burning of organic fuels is considered wasteful for the production of electricity, the share of thermal power plants in the total electricity generation in the country is about $95 \%$. Currently, the process of upgrading the equipment at the TPP is underway. So, if before the modernization of some thermal power plants, the consumption of burned conventional fuel per $1 \mathrm{~kW}$ of power was $450-500$ grams, then after replacing it with combined-cycle gas plants, these figures decreased to 240 grams. The transition in the future to the development of endless reserves of wind and solar energy for electricity production will significantly reduce the cost of organic fuel and electric energy in its production.

The energy loss on the lines is the difference in electricity released to the network by producers (stations), measured by meters at their output and usefully used, measured by the total reading of meters at the input of all consumers and paid for by them. These losses are called general or relatively general, which, for the sake of convenience of their analysis, are divided into technological and commercial components. Relatively total losses are expressed as a percentage of the useful energy released into the network [6-10].

Technological losses on power transmission lines (power lines) are determined only by calculation. Their appearance is explained by the physical processes of transmission and distribution of electricity: joule losses in the conductors of power lines, transformer windings, which are spent on heating the conductors, are proportional to the resistance of the conductors and the square of the current (depend on the values of the load 
and reactive energy); energy losses in the magnetic circuit of transformers are conditionally constant (do not depend on the values of loads), which are spent on heating the magnetic circuit of the transformer [11-15].

Commercial losses - the difference between total and technological losses, expressed in $\mathrm{kWh}$ or as a percentage of total losses.

All over the world, the amount of total losses, depending on various factors - geographical location, political, economic and social structure of the country ranges from 4-5\% (USA, Canada, Japan, South Korea) to $30-37 \%$ (South America, Africa). In the countries of Western Europe, this indicator does not exceed 6-7\%, in the Russian Federation 11-13\%, in other CIS countries this indicator is $12-20 \%$ or more [8, 15-19].

The purpose of the work is to reduce electricity losses in the Republic and increase their energy efficiency while optimizing the consumption of reactive power. Development of recommendations for reducing line losses and intra-plant electricity losses.

\section{Research methods}

A great contribution to the development of methods for calculating indicators of quality and energy losses was made by I.A. Budzko, V.E. Vorotnitsky, O. G. Mushroom, N. D. Grigoriev, I. V. Zhezhelenko, Yu.S. Zhelezko, F.D. Kosoukhov, V.G. Kuznetsov, M.S. Levin and others.

Minimization of relative total energy losses, in particular commercial losses, in developed countries is achieved by introducing the latest achievements of science, technology and technology in the process of control, accounting and sale of electricity. Thus, the process of implementing automated systems for monitoring and accounting of electricity (ASMAE) at the site of individual consumers of JSC "Tashgorpes"(Mirza Ulugbek district), which began in 2010, showed the wide possibilities of this innovation: facilitating the process of returning funds for the released electricity to consumers, improving indicators for reducing commercial and general losses. This is achieved by introducing electronic meters for consumers with devices for automatic data transmission to the control room and disconnecting when the payment for the used electricity is delayed by the consumer (in accordance with the "Electricity Supply Contract"). There is a reduction in the staff of unnecessary supervisors. Unfortunately, despite the fact that starting in 1996, a number of Government resolutions were issued within twenty years, obliging the introduction of ASMAE in the energy system of the Republic, these measures are being implemented at a slow pace under various "pretexts". If we achieve the full implementation of a single automated control system at power generation enterprises, power transmission lines, consumer enterprises and in everyday life, with the inclusion of integrated dispatch control systems, we can expect not only a significant reduction in commercial electricity losses, a reduction in the number of controllers, but also conduct a detailed analysis to identify and eliminate the causes of high values of total, including commercial losses, their components in any individual sections of the country's energy system [20].

Minimization of technological losses of the power line in our country is achieved mainly by reducing the reactive power in the transmission lines connecting electricity producers and consumers. At the same time, through the efforts of the supervision organizations, the energy consumer enterprises set the power factor at the entrance of their enterprise about one $(\cos \varphi>0.95)$.

If the consumer does not meet the established minimum value of the power factor at the entrance of the enterprise, the supervisory organizations impose penalties.

To encourage the maintenance of the established minimum value of the power factor at the input of the consumer, it is necessary to introduce a special tariff system for paying for electricity. For example, if $\cos \varphi>$ 0.95 , the tariff for electricity used should be minimal, and if it decreases below the minimum value, the tariff should increase stepwise. I.e., it is necessary to approve a differentiated table of tariffs for electricity used, depending on the power factor at the entrance of the enterprise. The implementation of the ACMAE mentioned above will allow you to make payments for the released electricity automatically. This should encourage consumers to increase the power factor of the load and thus lead to a reduction in electricity losses.

Today, the maintenance of the required value of the power factor $\cos \varphi$ at the input of the consumer is provided mainly by compensating the reactive power (static compensators, synchronous motors and synchronous compensators) [21-24], necessary to create a magnetic flux in transformers (Tr) and asynchronous motors (AM) of consumers. At the same time, in the literature, the issues of implementing the results of research to reduce the magnitude of power losses within the enterprises themselves (in-plant losses) are not particularly emphasized, while the energy audit of individual large enterprises in our country shows that they reach $7-8 \%$ of the active power consumed.

In-plant energy losses are made up of electrical energy losses generated mainly by:

a) joule losses in the wires of cable lines, windings of electrical machines and transformers that heat them;

b) magnetic losses in electrical machines and transformers created due to the magnetization reversal of magnetic systems (the phenomenon of hysteresis and eddy currents), which heat the magnetic systems;

c) other losses that exist due to the presence of rotating motor elements, the presence of higher harmonic components of currents, and the asymmetry of the applied voltage.

\section{Results and discussion}

A. The joule losses proportional to the active resistance of the wires and the square of the current determined by the Joule-Lenz law $(\mathrm{r} \bullet \mathrm{I} 2)$ are composed of the losses created in the conductors from the active Ia and reactive Ip components of the current. Among them, the losses in 
the AM and $\mathrm{Tr}$ windings are $40-50 \%$ of the losses in electric machines and transformers [7,9]. The active components of the current in them serve to perform useful work by the electrical equipment of the production mechanism, and energy losses from their flow in the wires are inevitable. The possibilities of minimizing theselosses will be discussed below.

The reactive (inductive) components of the current, in addition to creating magnetic fluxes in the windings and magnetic circuit of electric machines and transformers, do not participate in creating any useful work in the technological process, but limit the flow of the active components of the currents Ia in the conductors and windings of electric machines and transformers.

The ratio of the currents Ia and Ip in different specific sections of the electrical circuit of the enterprise is determined by the power factor in this section $\cos \varphi$ to the subsequent analytical expression

$$
\cos \varphi=\not_{a}^{\&} /\left(\not_{a}^{\&}+P_{p}^{\&}\right)=I / \sqrt{I_{a}^{2}+I_{p}^{2}}
$$

Here, the points above I mean that the currents are expressed in vector quantities.

The reduction of the reactive (inductive) components of losses is mainly due to their compensation. This is achieved by creating reactive (capacitive) components of the current, i.e. using synchronous compensators (SC), synchronous motors (SM) or static capacitor compensators (CC).

In enterprises where there are no SM or SCS in the electrical equipment, a reactive power compensator from the CC is used. Usually, the CC and SC are connected to the input terminals of the power supply circuits of the enterprise (Fig. 1).

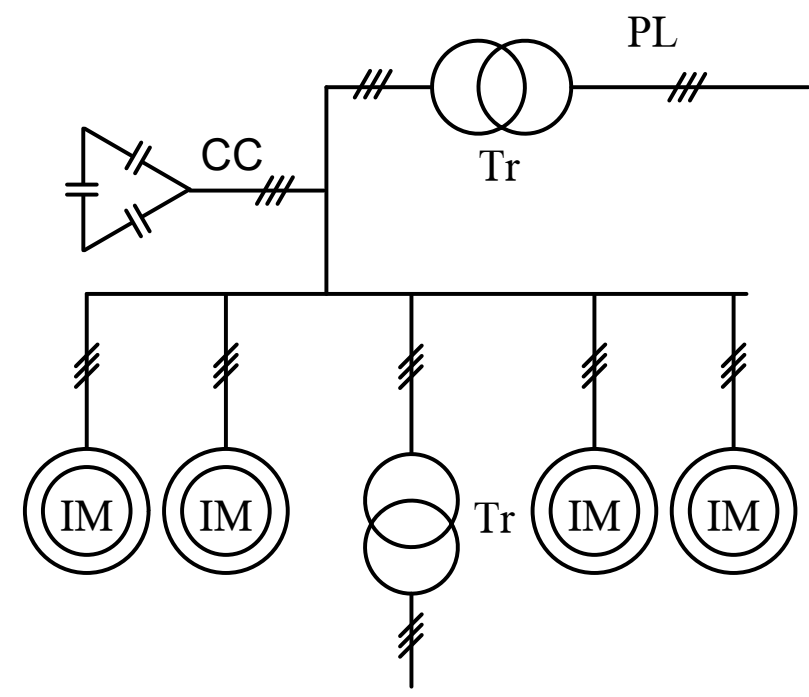

Fig. 1. The scheme of power supply of the enterprise with CC.

The reactive power required to create a magnetic flux in the $\mathrm{Tr}$ and $\mathrm{AM}$ inside the enterprise is generated and transmitted from the $\mathrm{CC}$ or SC. In this case, the external network is freed from reactive currents, the power factor of which is close to one. In-plant conductors will flow reactive currents (in addition to the active component current). They are combined with the active components of the load currents in the conductive busbars, cable lines, and windings of electric machines and transformers and heat them.

If the electrical equipment of the enterprise includes SM (ball mills, pumping stations), the compensation of the reactive power is carried out by changing the degree of excitation of the SM (capacitive mode). In this case, the reactive power required for $\mathrm{Tr}$ and $\mathrm{AM}$ is provided by the SM and when the reactive currents flow, Joule losses are created in the conductors.

The choice of these or other methods of reactive power compensation, given above, depends on the ratio of the length of the wires through which the reactive currents flow. As a rule, in large enterprises with SM, the length of cable lines connecting sources and consumers of reactive energy is hundreds sometimes thousands of meters. Reactive currents also pass through the windings of transformers located between the SM and AM. Therefore, for such enterprises - consumers of electricity, both methods do not lead to a significant reduction in in-plant losses. For example, inter-shop measurements of active and reactive power carried out at one of the enterprises of the country for a long time showed that at the entrance of the shops, the electrical equipment of which consists of SM, Tr and AM, the power factor ranges from 0.95 (capacitive nature) to 1.0 (due to full compensation of the reactive power in this shop). At the entrance of the workshops, the electrical equipment of which consists only of $\mathrm{AM}$ and $\mathrm{Tr}$, the power factor ranges from 0.4 to 0.7 .

To reduce Joule losses in large enterprises, this article suggests adopting methods based on:

a) minimizing the length of conductors with reactive currents;

b) minimizing the reactive current in the conductors.

Providing a reduction in the length of the conductors through which the reactive currents flow to compensate for the reactive power is possible as follows:

1. Synchronous motors in workshops, in addition to their direct purposes for converting electrical energy into mechanical work, must also serve to supply reactive power to D and Tr., located only in this workshop or at a close distance from the SM. In Fig. 2, this equipment is shown as a rectangle with dotted lines.

2. Each of the large AM located at a remote distance from the SM should be equipped with its own capacitor compensators (in Fig. 2, they are shown by rectangles 2 and 3 ).

3. A group of low-power electrical equipment located at a close distance from each other, but remote from the SM, must also be supplied with separate CC (in Fig. 2, rectangle 4).

At the input of each of the three groups of equipment specified, it is necessary to maintain a power factor of about one.

The optimal length of cable lines connecting sources and consumers of reactive power for each of the first and second groups of equipment can be calculated by comparing the indicators of technical and economic calculations of the use of SC or CC and the location, as 
well as the payback period of the implemented type of compensating device.

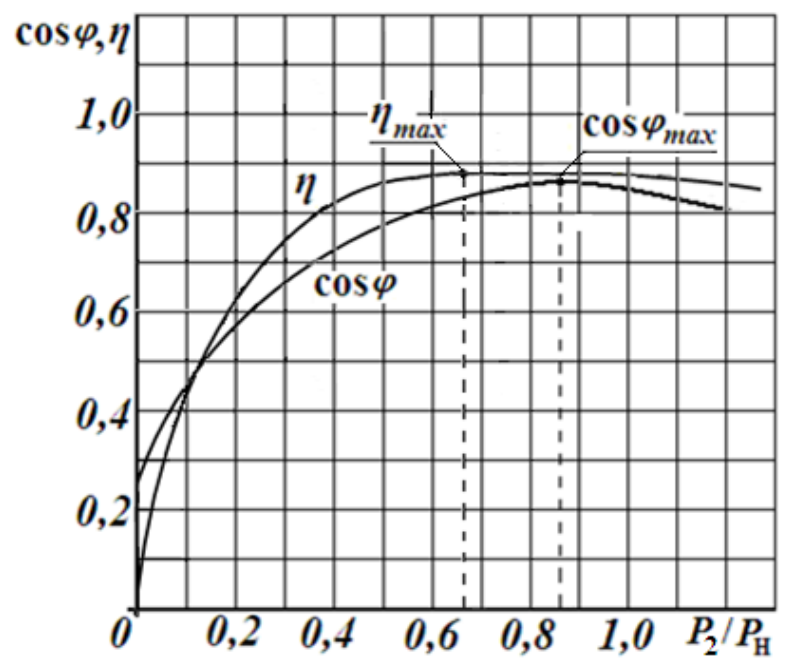

Fig. 2. Operating characteristics $\eta$ and $\cos \varphi$ of the asynchronous motor and transformer.

To ensure the minimum values of the reactive current in the conductor $\mathrm{x}$, it is possible in following way:

The value of the reactive (inductive) magnetizing current is determined by the required value of the magnetic flux created by the stator winding and the primary winding of the transformer, their installed capacities and the number of turns of the corresponding windings. With a constant value of the input voltage and a change in the load factor of an asynchronous motor or transformer, their reactive current remains unchanged. However, with the increase in the installed power of asynchronous motors and transformers, the values of the reactive components of the currents increase.

It is known that the performance characteristics are functions of the efficiency coefficient $n=f(\beta)$ and the power factor $\cos \varphi=\psi(\beta)$ in $\mathrm{AM}$ and $\operatorname{Tr}$ depending on the loading power

$$
\beta=P_{2} / P_{H}
$$

they have an extreme character of change, where both the useful power on the shaft and the rated power of the engine. At the same time, in asynchronous motors and transformers, the maximum values of the efficiency are observed at the value of the load and the power factor at $[3,4]$. Depending on the value of the installed power of the AM and $\mathrm{Tr}$, the maximum values and range from 0.8 to 0.94 and 0.75 to 0.92 [9], respectively. The low power coefficients at the input terminals of the workshops with $\mathrm{AM}$ and $\mathrm{Tr}$, mentioned above, indicate an insufficient workload and underutilization of AM and Tr with an overestimated installed capacity. Consequently, in these $\mathrm{AM}$ and $\mathrm{Tr}$, the reactive (inductive) power is also overestimated.

The characteristic $n=f(\beta)$ has such an extreme part shape that the value changes by only a few percent in the segment. In contrast to the shape of the curve, it has a pronounced extremum and within the specified load limits, the power factor differs from its maximum value by several tens of percent. This indicates that at low values of the load of $\mathrm{AM}$ and $\mathrm{Tr}$, their reactive power, although it remains unchanged, the share of the reactive component in the resulting current increases with decreasing values, therefore, the reactive component of Joule losses will increase.

The use of asynchronous motors and transformers with reduced installed capacities close to the nominal value will reduce their reactive currents to minimum values.

B. Magnetic losses in asynchronous motors and transformers, created as a result of the flow of alternating magnetic flux in their magnetic core, account for $40-$ $45 \%$ of the total losses in electric machines and transformers [9, 23-24]. It is known that the magnetic losses caused by the phenomenon of hysteresis and eddy currents are proportional to the magnitude of the magnetic flux to the nth degree. Minimization of these losses is proposed to be carried out by reducing the magnitude of the magnetic flux in the AM and Tr to their optimal values, which is carried out by reducing their installed capacity, discussed above.

C. Other types of in-plant losses that exist due to the presence of rotating motor elements, higher harmonic components of currents in the wires, the asymmetry of the applied voltage, and all other types of losses, the direct measurement of which is practically impossible, account for up to $10 \%$ of the total plant losses.

The reduction of mechanical losses caused in electric machines is spent on the friction of rotating parts on air (ventilation), bearings, etc. are regulated by the conditions of their operation.

The scheme of power supply of a large enterprise of $\mathrm{SM}$ and CC is proposed, which is shown in Fig. 3.

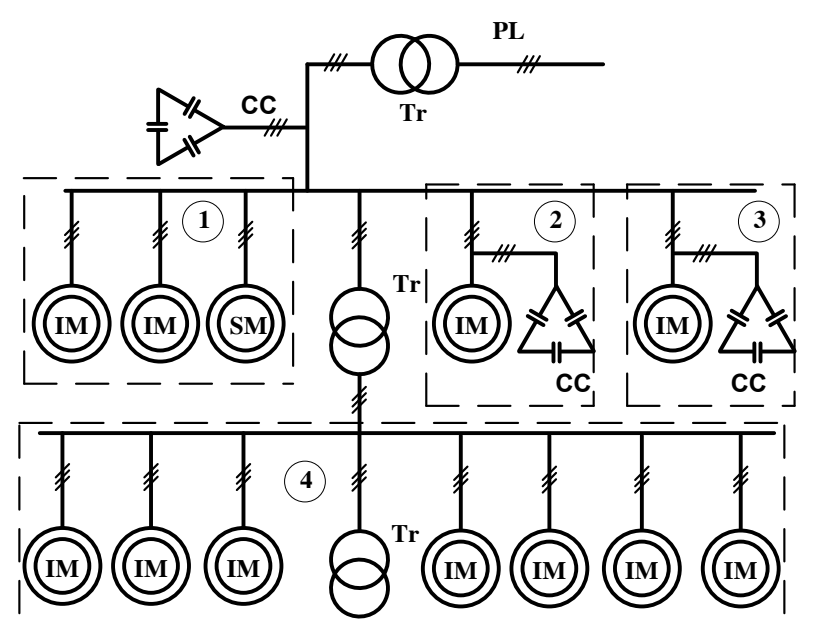

Fig. 3. The proposed scheme of power supply of a large enterprise of SM and CC.

Sinusoidality and non-symmetry of the voltage is an important indicator of the quality of electricity, which is provided by the power supply company-primary sources of electricity (synchronous generators) produce a voltage of almost sinusoidal and symmetrical shape. The higher harmonic components of the currents and the nonsymmetry of the voltage are created by the electricity 
consumer himself. Higher harmonic currents are created by the nonlinear nature of the load, which include static current form converters (thyristor rectifiers, thyristor frequency converters-inverters, electric welding units, etc.). Higher harmonic components of currents create additional power losses in electrical equipment and on power lines. The non-symmetry of the voltage is created by the consumer of single-phase switching on of lighting and other types of load, the consequence of which is the occurrence of additional losses.

The above losses will be quite significant with a large distortion factor of the sinusoidal voltage and current curves. To ensure a small distortion of the sinusoidal voltage and current curves, the power of the power supply must be at least ten times greater than the power of the nonlinear load. These conditions are fully met in the newly introduced devices-frequency-controlled electric drives of technological processes of large industrial enterprises.

\section{Conclusion}

Thus, as a result of the analysis, the ways to reduce the loss of electricity in the system of its production, distribution, transmission and consumption in industrial enterprises are determined:

1. It is necessary to accelerate the pace of implementation of the ASMAE in the process of production, transmission, distribution of electricity, which allows:

- automate the process of production, accounting, transmission, sales (refund of funds for the released electricity);

- conduct regular remote measurement and analysis of technological and commercial losses in individual sections of the power system.

2. Despite the fact that the burning of organic fuels for electricity production is considered wasteful, the share of thermal power plants in the total volume of electricity generation in the country today is about $90 \%$. If we assume that the absolute values of these values for thermal power plants remain unchanged, the transition to the development of infinitely large reserves of wind and solar electricity will significantly reduce the relative fuel consumption in electricity production.

3. To reduce the reactive component of the current in cable lines within enterprises, it is necessary to correctly choose the installed power of $\mathrm{AM}$ and $\mathrm{Tr}$ when designing them. Existing equipment with excessive installed capacity must be replaced in the course of current or major repairs with equipment that operates with a rated load.

4. It is necessary to reduce the length of cable lines through which reactive currents flow. To do this, each large AM and Tr located at a remote distance from the DM must be provided with individual CC. A group of low-power electrical equipment located at a close distance from each other should also be provided with a separate CC.

The scientific novelty of the work is as follows:
- The dependences of the relative change in the transmission capacity, power losses and voltage losses with a change in the reactive power factor in the DC have been obtained.

- The ranges of loads, at which it is advisable to replace lightly loaded asynchronous motors and power transformers, differing from those accepted in practice by a lower critical value of the load factor, have been clarified.

\section{References}

1. T.S. Kamalov, Frequency-regulated electric drive of pumping stations of machine irrigation systems, Monograph (Tashkent: Fan, 368, 2014)

2. M.S. Elchieva, B.K. Karybekova, Ways to reduce energy losses in electrical networks, Izvestiya Osh Technological University, 2, 26-30 (2017)

3. J.L. Viegasa, P.R. Esteves and et all, Solutions for detection of non-technical losses in the electricity grid: A review, Renewable and Sustainable Energy Reviews, 80, 1256-1268 (2017) DOI: 10.1016/j.rser.2017.05.193

4. P. Antmann, Reducing technical and nontechnical losses in the power sector (background paper for the World Bank Group energy sector Strategy), Tech. rep. (2009)

5. A.G. Marinopoulosab, M.C. Alexiadisb, P.S. Dokopoulosb, Energy losses in a distribution line with distributed generation based on stochastic power flow, Electric Power Systems Research, 81 (10), 1986-1994 (2011) DOI: 10.1016/j.epsr.2011.06.006

6. J.L. Viegasa, P.R. Esteves, Solutions for detection of non-technical losses in the electricity grid: A review, Renewable and Sustainable Energy Reviews, 80, 1256-1268 (2017) DOI: 10.1016/j.rser.2017.05.193

7. S. Adams, F. Atsu, E.M. Klobodu, L. Richmond, Electricity transmission, distribution losses and economic growth in South Africa, Heliyon, 6, e05564 (2020) DOI: 10.1016/j.heliyon.2020.e 05564

8. V.P. Kulichenkov, How to reduce energy losses, Energy strategy, Minsk, 3, 20-24 (2010)

9. K.R. Allaev, Energy of the world and Uzbekistan, Analytical review (Tashkent, 380, 2016)

10. I.P. Kopylov, Electric machines (Moscow: Energy, 2004)

11. D. Schönheit, C. Dierstein, D. Möst, Do minimum trading capacities for the cross-zonal exchange of electricity lead to welfare losses? Energy Policy, 149, 112030 (2021) DOI: 10.1016/j.enpol.2020.112030

12. N. Farrell, The increasing cost of ignoring coase: Inefficient electricity tariffs, welfare loss and welfare-reducing technological change, Energy Economics, $104848 \quad$ (2020) DOI: 10.1016/j.eneco.2020.104848

13. Lucas de Oliveira Ventura, et all, A new way for comparing solutions to non-technical electricity 
losses in South America, Utilities Policy, 67, 101113 (2020) DOI: 10.1016/j.jup.2020.101113

14. G. Farshchiana, S.A. Darestanibc, N. Hamidi, Developing a decision-making dashboard for power losses attributes of Iran's electricity distribution network, Energy, 216 (1), 119248 (2021) DOI: $10.1016 / j$.energy.2020.119248

15. A. Dasa, A. McFarlaneb, Non-linear dynamics of electric power losses, electricity consumption, and GDP in Jamaica, Energy Economics, 84, $104530 \quad$ (2019) DOI: 10.1016/j.eneco.2019.104530

16. H. Afrisal, B. Setiyono, M.F. Yusuf, R.M. Suin, O. Toirov, 7th International Conference on Information Technology, Computer, and Electrical Engineering (ICITACEE), 41-46 (2020)

DOI: 10.1109/ICITACEE50144.2020.9239228

17. A.G. Marinopoulos, M.C. Alexiadis, P.S. Dokopoulos, Energy losses in a distribution line with distributed generation based on stochastic power flow, Electr. Pow.Syst. Res., 81 (10), 1986-1994 (2011)

18. M.T. Costa-Campi, D. Daví-Arderius, E. TrujilloBaute, The economic impact of electricity losses, Energy Economics, 75, 309-322 (2018) DOI: 10.1016/j.eneco.2018.08.006

19. D. Bystrov, O. Toirov, G. Mustafakulova, D. Yakubova, NISS2020: Proceedings of the 3rd International Conference on Networking, Information Systems \& Security, 54, 1-3 (2020) DOI: $10.1145 / 3386723.3387873$

20. D. Bystrov, O. Toirov, S. Giyasov, M. Taniev, U. Sardor, NISS2020: Proceedings of the 3rd International Conference on Networking, Information Systems \& Security, 49, 1-4 (2020) DOI: $10.1145 / 3386723.3387868$

21. K. Alimkhodjaev, O. Toirov, M. Taniev, S. Alimkhodjaev, Addressing Issues and Possibility of Introducing Renewable Energy Sources in the Conditions of Uzbekistan, JCR, 7 (15), 17211728 (2020) DOI: $10.31838 /$ jcr.07.15.231

22. O. Toirov, U. Mirkhonov, Overview of Compressor Installations and Issues of Their Energy saving, International Journal of Advanced Research in Science Engineering and Technology, 6 (10), 11446-11452 (2019)

23. O. Toirov, U. Mirkhonov, Principles for Controlling the Excitation of Synchronous Motors of the Compressor Installation, International, Journal of Advanced Research in Science, Engineering and Technology, 7 (5), 13876-13881 (2020)

24. O. Toirov, A. Bekishev, S. Urokov, U. Mirkhonov, E3S Web of Conferences, 216, 01116 (2020) DOI: 10.1051/e3sconf/202021601116

25. O. Toirov, K. Alimkhodjaev, N. Pirmatov, A. Kholbutaeva, E3S Web of Conferences, 216, 01119 (2020) DOI: 10.1051/e3sconf/202021601119. 